\title{
Perceived emotional intelligence and life satisfaction: the mediating role of the positivity ratio
}

\author{
Marcin Moroń \\ Department of Social and Environmental Psychology, Institute of Psychology, University of Silesia, Katowice, Poland
}

BACKGROUND

Emotional intelligence is a positive predictor of well-being, and positive and negative affect were demonstrated to mediate this relationship. In two studies the balance between positive and negative affect (positivity ratio) is examined as a mediating factor between perceived emotional intelligence and satisfaction with life.

\section{PARTICIPANTS AND PROCEDURE}

Three-hundred and sixteen individuals (50\% female) participated in the first study. Participants completed the Self-perceived emotional intelligence questionnaire, the Positive and negative affect scale, and the Satisfaction with life scale. One hundred individuals (79\% women) participated in the second study. In the first measurement participants completed the Emotional intelligence questionnaire, the general Positive and negative affect scale, and the Satisfaction with life scale, while in the second measurement participants completed the Positive and negative affect in the past week scale and the Satisfaction with life scale.

\section{RESULTS}

In the first study perceived emotional intelligence was positively correlated with positivity ratio and satisfaction with life, while positive ratio mediated between perceived emotional intelligence and satisfaction with life. In the second study, perceived emotional intelligence was positively correlated with satisfaction with life and positivity ratios in both measurements. The relationships between perceived emotional intelligence and satisfaction with life (Time 2) were fully mediated by satisfaction with life (Time 1), and sequentially by positivity ratio (general) and satisfaction with life (Time 1), and positivity ratio (general) and positivity ratio (Time 2 ).

\section{CONCLUSIONS}

Individuals with high emotional intelligence tend to be more satisfied with their lives, while higher positivity ratio mediated between perceived emotional intelligence and satisfaction with life.

\section{KEY WORDS}

emotional intelligence; satisfaction with life; mediation; positive affect; negative affect

Corresponding Author - Marcin Moroń, Department of Social and Environmental Psychology, Institute of Psychology, University of Silesia, 53 Grażyńskiego Str., 40-126 Katowice, Poland, e-mail: moron.marcin@gmail.com AUthors' CONTRIBUtions - A: Study design - B: Data collection · C: Statistical analysis · D: Data interpretation .

E: Manuscript preparation · F: Literature search · G: Funds collection

To Cite this ARTiCLE - Moroń, M. (2018). Perceived emotional intelligence and life satisfaction: the mediating role of the positivity ratio. Current Issues in Personality Psychology 6(3), 212-223.

RECEIVED 11.10.2017 · REVIEWED 13.01.2018 · ACCEPTED 29.03.2018 · PUBLISHED 21.05.2018 


\section{BACKGROUND}

In recent decades, a growing interest with regard to examining the role of emotional intelligence (EI) for important life outcomes has been observed. An evergrowing body of research shows the significant positive correlations between EI, subjective affective, and cognitive well-being, e.g. the mental, the psychosomatic, and the physical health (cf. relevant meta-analysis by Andrei, Siegling, Aloe, Baldaro, \& Petrides, 2016; Martins, Ramalho, \& Morin, 2010; Sánchez-Álvarez, Extremera, \& Fernández-Berrocal, 2016; Schutte, Malouff, Thorsteinsson, \& Rooke, 2007). The significant link between EI and subjective well-being appears both in cross-sectional and prospective studies (Extremera \& Fernández-Berrocal, 2005; Ruiz-Aranda, Pineda-Galán, \& Salguero, 2011; Gallagher \& Vella-Brodrick, 2008; Palmer, Donaldson, \& Stough, 2002; Saklofske, Austin, \& Minski, 2003; Schutte \& Malouff, 2011). These results corroborate the initial assumptions concerning the role of EI, according to which the emotional skills that encompass the EI construct help to use emotional information better, cope with daily stress more effectively, and achieve a greater life satisfaction (Mayer \& Salovey, 1997; Salovey, Bedell, Detweiler, \& Mayer, 1999).

Currently, three predominant approaches to defining and measuring EI can be distinguished: the ability model of EI with performance-based measurements (e.g. MSCEIT v2.0; Mayer, Salovey, \& Caruso, 2002), the perceived EI (PEI) with self-report measurements that are based on the ability model of EI (e.g. Trait Meta-Mood Scale, TMMS: Salovey, Mayer, Goldman, Turvey, \& Palfai, 1995; Emotional Intelligence Scale, EAS: Schutte et al., 1998; Wong and Law Emotional Intelligence Scale, WLEIS: Wong \& Law, 2002), and the trait EI, also referred to as the mixed model of EI (Petrides \& Furnham, 2000). In their recent metaanalysis, Sánchez-Álvarez et al. (2016) demonstrated that self-report ability EI, namely the perceived EI (PEI; Sánchez-Álvarez, Extremera, \& Fernández-Berrocal, 2015), had a positive and significant correlation with the indicators of subjective cognitive and affective well-being of a magnitude close to the correlation obtained for trait EI measures, and higher than the correlation obtained for ability-based EI measures. Scores in questionnaires in mixed/trait EI approach give an estimation of various traits, behavioural dispositions, and self-evaluations in the area of social functioning (Petrides, 2011), which is usually regarded as a drawback of this approach (Salovey et al., 1999). PEI refers to a self-reported level of emotional skills (emotion perception, facilitation of thought, understanding, regulation; cf. Elfenbein \& MacCann, 2017), which could also be called the emotional self-efficacy (Sánchez-Álvarez et al., 2015).
This study focuses on the role of PEI in subjective well-being and seeks mediating factors in the PEI well-being relationship.

Zeidner, Matthews, and Roberts (2012) proposed one of the factors that could mediate between EI and subjective well-being to be affective balance. The rationale of this mediatory model is based on the assumption that emotional abilities contribute to experiencing fewer negative emotions (e.g. social anxiety) and more positive emotions, which in turn leads to higher satisfaction with life. Positive and negative emotionality, referred to as the affective component of subjective well-being (Lucas, Diener, \& Suh, 1996), depends primarily on the frequency of positive and negative affective experiences (Diener, Colvin, Pavot, \& Allman, 1991; Diener, Sandvik, \& Pavot, 1990; Karademas, 2007), and serves as an important source of judgments about life satisfaction (Kuppens, Realo, \& Diener, 2008; Schimmack, Oishi, \& Diener, 2002; Schimmack, Radhakrishnan, Oishi, Dzokoto, $\&$ Ahadi, 2002). Previous experimental and cross-cultural studies confirmed the causal influence of affectivity on life satisfaction judgements (Schwartz \& Clore, 2007). Numerous propositions also stressed the role of the so-called "positivity ratio", namely the ratio of pleasant feelings and sentiments to unpleasant ones over time (Fredrickson \& Losada, 2005; Gottman, 1994; Schwartz et al., 2002), in predicting cognitive evaluations of one's life (Diener, 2000). Despite the existence of a substantial debate concerning the shape of the relationship between the positivity ratio and the subjective well-being (linear, nonlinear, or curvilinear; see Basińska \& Gruszczyńska, 2017; Brown, Sokal, \& Friedman, 2013, 2014), it seems to be well-confirmed that a higher positivity ratio is (at least to some point) beneficial for satisfaction with life and other important life outcomes (Fredrickson, 2013). Shrira et al. (2011) have demonstrated that a moderate positivity ratio is sufficient for optimal functioning in the midst of stress. The positivity ratio is correlated with optimism, and if not "excessive", it predicts creativity (Rego, Sousa, Marques, \& Cunha, 2012). Low level of positivity ratio could be regarded as a symptom of depression, while the balance of $62 \%$ of positive cognition or affect correlates with general psychological adaptation (Schwartz et al., 2002).

The model of affective mediators (the positive and negative affects) between EI and subjective cognitive well-being has been confirmed in several studies (Gignac, 2006; Kong \& Zhao, 2013; Extremera \& Rey, 2016). Kafetsios and Zampetakis (2008) showed that positive and negative affect at work acted as mediators of the relationship between EI and job satisfaction. Gignac (2006) and Kong and Zhao (2013) demonstrated that the following mediation linkage: emotional intelligence $\rightarrow$ positive affect $\rightarrow$ satisfaction with life is significantly stronger than mediation through negative affect. Both in studies by Gig- 
nac (2006) and Kong and Zhao (2013), positive and negative emotions were treated independently. The abovementioned role of the positivity ratio (Diener, 2000; Fredrickson, 2013; Schwartz et al., 2002) could bring another perspective to the study of affective mediators between EI and well-being. One may propose that people high in EI could maintain a beneficial positivity ratio, which helps them feel satisfied with their lives. Some confirmation for these assumptions comes from a two-year longitudinal study by Sánchez-Álvarez et al. (2015), who demonstrated that attention to emotion, clarity of emotion, and repair (domains of TMMS, which is a measure of PEI; Salovey et al., 1995) predict negative and positive affect in one-year periods and, through mediation, significantly affect life satisfaction. Short-term designs of similar mediation models are lacking in literature.

\section{THE PRESENT STUDY}

The present study focuses on two rationales. Its first aim was to examine the mediating role of positivity ratio in the relationship between perceived emotional intelligence (PEI) and life satisfaction. It was hypothesised that PEI will be positively correlated with positivity ratio, and that positivity ratio would be positively correlated with satisfaction with life, and that the indirect path between PEI and satisfaction with life via positivity ratio would be significant. The second goal was to investigate this mediation in a short-term longitudinal study (one week). It was hypothesised that PEI would be a significant predictor of the positivity ratio and satisfaction with life in both measurements (at the beginning and end of a week), and that in both measurements an indirect effect of PEI $\rightarrow$ positivity ratio $\rightarrow$ satisfaction with life would be significant. Additionally, more complex patterns of mediation will be examined using the multiple mediation model, controlling for stability of the positivity ratio and life satisfaction.

\section{STUDY 1}

\section{PARTICIPANTS AND PROCEDURE}

The participants were 158 women and 158 men aged between 13 and 56 years $(M=22.68, S D=4.93)$. The educational and material status of the participants was not directly controlled for, but secondary and higher education was predominant among the participants. For the purpose of enlargement of the number of participants and increasing the statistical power of the analysis ${ }^{1}$ two methods were used to invite the participants: a face-to-face request and a request via e-mail. About $40 \%$ of the participants were contacted via Internet $(n=127)$, and the remaining part was contacted individually and completed a paper-and-pencil version of the questionnaires. There were no significant age-related differences between the participants who had completed the scales via Internet and in individual contact, $F(3,315)=1.45, p=.228$; similarly, there were no significant differences in: PEI, $F(3,315)=0.12 ; p=.948$; positivity ratio, $F(3,315)=0.93 ; p=.426$, and satisfaction with life, $F(3,315)=0.02 ; p=.996$. There was a significant difference in gender ratio. In the Internet subsample there were 102 women $(80.32 \%)$, while in the paper-and-pencil subsample there were 56 women (29.63\%), $\chi^{2}(1)=78.06, p<.001, \varphi=.50$. This difference was addressed in a subsequent analysis by controlling for gender. The accepted methodology of inviting participants resulted in a diversified sample with a relatively broad age span. According to the large-scale study by Baird, Lucas, and Donnellan (2010), life satisfaction does not decline over much of adulthood, and a steep decline in life satisfaction appears among those older than 70 years (Baird et al., 2010). Charles, Reynolds, and Gatz (2001) showed that for positive affect, the younger and middle-aged adults showed marked stability, but the older group (over 60-year-olds) showed a small decrease over time. The negative affect decreased with age, although the rate was attenuated among the oldest adults (over 60 years of age). Concurrently, Diehl, Hay, and Berg (2011) showed a decrease in the negative affect and an increase in the positive affect between young adults (about 26 years old), middle-aged adults (about 52 years old), and older adults (about 71 years old), where the oldest group possessed the highest positivity ratio. The studies on the German population examined the frequency of discrete emotion in life-span. The frequency of anger increases during young adulthood, then drops to the level of the early 20 s, and then shows a decrease in over 50 s. The frequency of sadness remains stable over most of adulthood. Also, there was a steady decrease in happiness across age groups, but a within-person decline in happiness was only evident in old age (Kunzmann, Richter, \& Schmukle, 2013). Based on these results, age was also chosen to be entered as covariate to analyses for both the dependent and mediator variables.

\section{MEASURES}

The self-rated emotional intelligence scale, SREIS (Brackett, Rivers, Shiffman, Lerner, \& Salovey, 2006; Author's translation), consisting of four subscales, represents the emotional abilities mentioned in the ability model of emotional intelligence (Mayer, Roberts, \& Bersade, 2008). The perceiving emotion subscale consists of four items (e.g. "I am aware of the nonverbal messages other people send"), the Use of 
emotion subscale - of three items (e.g. "When making decisions, I listen to my feelings to see if the decision feels right"), the Understanding emotion subscale, comprising four items (e.g. "I have a rich vocabulary to describe my emotions"), and the Managing emotion subscale, split into a scale that refers to oneself (four items; e.g. "I can handle stressful situations without getting too nervous") and one that refers to managing others' emotions (three items; e.g. "I know the strategies to make or improve other people's moods"). Translation was made with reference to the ability approach to emotional intelligence (Meyer et al., 2008) and to other Polish measurements of PEI (e.g. INTE; Jaworowska \& Matczak, 2001). The items were rated on a five-point Likert-type scale from 1 = very inaccurate to 5 = very accurate. Following the approach of Brackett et al., the general score was used. In the present study, the reliability of SREIS general score was $\alpha=.78$.

Positive affect and negative affect in participants were assessed with a version of the Positive Affect and Negative Affect Scale (PANAS; Kuppens et al., 2008; Author's translation). The scale, consisting of a 14-word list, comprises eight negative affect labels (i.e. sadness, anger, guilt, shame, worry, stress) and six positive affect labels (i.e. pleasure, happiness, pride, gratitude, love). Items were translated with reference to other Polish scales measuring affective responding (Brzozowski, 2010; Wojciszke \& Baryła, 2005) and to ensure comprehensibility. Participants were instructed to indicate the extent to which they generally experience each affect using a seven-point Likert-type scale from 1 = very slightly or not at all to $7=$ very much. Similarly to the abovementioned measures, an individual score was an average of results per subscale. In this study, Cronbach's $\alpha$ for negative affect was as follows: $\alpha=.87$, and for positive affect it was: $\alpha=.77$. The positivity ratio was computed by dividing the score for positive affect by the score for negative affect (cf. Fredrickson, 2013).

The satisfaction with life scale, SWLS (Diener, Emmons, Larsen, \& Griffin, 1985; Polish adaptation: Juczyński, 2001). The scale consists of five items (e.g. "I am satisfied with my life; in most ways my life is close to my ideal"). Each item is rated on a seven-point Likert type scale ranging from 1 = strongly disagree to 7 = strongly agree. In the present study average for items were used. The internal consistency of SWLS amounted to $\alpha=.84$.

\section{RESULTS}

Descriptive statistics for perceived emotional intelligence, positivity ratio and satisfaction with life are presented in Table 1.

The participants rated the positive affect significantly higher, $M=4.81, S D=1.00$, than the negative affect, $M=3.51, S D=1.21, t(315)=-14.58, p<.001$, $d=.91$. The positivity ratio ranged from 0.43 to 5.33 .

The regression analysis with bootstrap procedures for estimation of indirect effects implemented in PROCESS macro (Hayes, 2013) was carried out. The positivity ratio was tested as a mediator variable, while age and gender were controlled for. The bias-corrected confidence interval estimation method and 10,000 bootstrapping samples were used. The total regression model was significant, adj. $R^{2}=.24$, $F(4,311)=24.53, p<.001$. The direct effect of PEI on satisfaction with life was significant, $b=.34, S E=.15$, $t=2.31, p=.022, \beta=.12$. Positive ratio was a significant predictor of satisfaction with life, $b=.80$, $S E=.10, t=8.35, p<.001, \beta=.44^{2}$. Gender was also a significant predictor of satisfaction with life, $b=.34$, $S E=.13, t=2.61, p=.010, \beta=.13$. The indirect effect of $\mathrm{PEI} \rightarrow$ positivity ratio $\rightarrow$ satisfaction with life was significant, $b=.38, S E=.08,95 \% \mathrm{CI}=[.23 ; .56]$ and is presented in Figure 1A.

\section{DISCUSSION}

The aim of the study was to investigate the mediating role of the positive ratio in the relationship between perceived emotional intelligence and satisfaction with life. As was predicted, perceived emotional intelligence was positively correlated both with positive ratio and with satisfaction with life, which is in line with the results of numerous studies (Andrei et al., 2016; Gignac, 2006; Kong \& Zhao, 2013; Sánchez-Álvarez et al., 2016). People who are confident about their emotional abilities may be aware of a necessity to bal-

Table 1

Means, standard deviations and correlations between PEI, positivity ratio, and satisfaction with life

\begin{tabular}{lccccccc}
\hline & $M$ & $S D$ & PEI & $\begin{array}{c}\text { Positivity } \\
\text { ratio }\end{array}$ & $\begin{array}{c}\text { Satisfaction } \\
\text { with life }\end{array}$ & Gender & Age \\
\hline PEI & 3.40 & 0.46 & $.29^{* * *}$ & $.26^{* * *}$ & .03 & .08 \\
Positivity ratio & 1.57 & 0.72 & & $.46^{* * *}$ & $-.13^{*}$ & -.01 \\
Satisfaction with life & 4.00 & 1.32 & & & .08 & .02 \\
\hline
\end{tabular}

Note. PEI - perceived emotional intelligence. Gender is coded: $0=$ men, $1=$ women. Positivity ratio = positive affect $/$ negative affect. ${ }^{*} p<.05,{ }^{* * *} p<.001$ (two-tailed) 
A
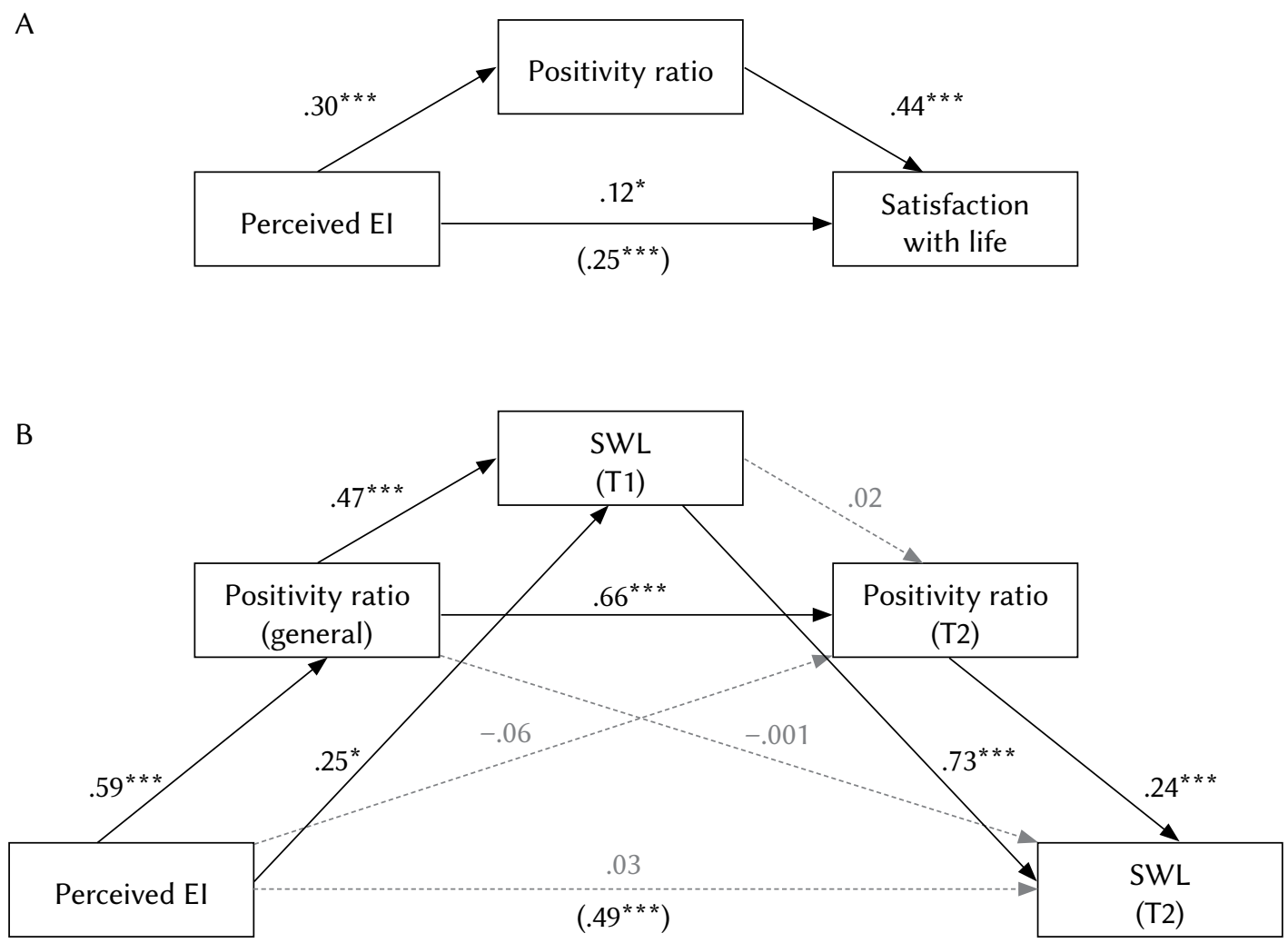

Note. Paths values represent standardised regression coefficients. The coefficient in parentheses denotes a direct effect of El on satisfaction with life when the positivity ratio and other mediators are not entered in the regression model. In panel B, the grey and dotted paths represent insignificant regression coefficients. Results are controlled for age and gender. ${ }^{*} p<.05,{ }^{* *} p<.01,{ }^{* * *} p<.001$

Figure 1. The mediating effects of positive ratio on perceived emotional intelligence (EI) and satisfaction with life relationship (SWL) in Study 1 (A) and Study 2 (B).

ance affective experiences and may also implement effective strategies to regulate their mood (cf. Szczygieł \& Mikolajczak, 2017). Individuals with high emotional intelligence may also develop a high social competence (Szczygieł \& Weber, 2017), which could help them maintain a beneficial balance of relationships with others (Lee, Watson, \& Dams-O'Connor, 2017). Additionally, the beneficial role of positive ratio for cognitive well-being was also confirmed (cf. Fredrickson, 2013; Fredrickson \& Losada, 2005; Rego et al., 2012; Shrira et al., 2011). Although the hypothesis about the mediating role of positive ratio was confirmed, the mediation could not be regarded as full. After entering positivity ratio into the regression model, PEI remained a significant predictor of satisfaction with life. According to the propositions of Zeidner et al. (2012), one may suggest that, beyond affective factors, other processes may mediate between PEI and life satisfaction. The coping process (MacCann, Fogarty, Zeidner, \& Roberts, 2011; Zeidner, Matthews, \& Roberts, 2006) and social support (Zeidner \& Matthews, 2016) could be seen as reasonable candidates.

\section{STUDY 2}

\section{PARTICIPANTS AND PROCEDURE}

The participants were 100 undergraduate students (71\% women) aged between 18 and 23 years $(M=19.56, S D=1.10)$. From the perspective of the goal of Study 2, a focus was placed on the convenience sampling to ensure a high rate of participation in the second wave of measurement. For this reason, a sample of university undergraduates was invited to this study. A limitation of this procedure is that participants in Study 2 are on average younger compared to the participants of Study 1, but also constitute a more homogenetic group. The participants were contacted during classes and completed both measurements at the beginning of the classes in an interval of one week. The rationale of the selection of the week interval between measurements was twofold. First, Cornélissen et al. (2005) demonstrated circaseptan (weekly) rhythmicity in positive (lower pos- 
Table 2

Means, standard deviations, and correlations between PEI, positivity ratio (general and in the past week), and satisfaction with life (general and in the past week)

\begin{tabular}{|c|c|c|c|c|c|c|c|c|c|}
\hline & $M$ & $S D$ & PEI & $\begin{array}{c}\text { PR } \\
\text { (general) }\end{array}$ & $\mathrm{PR}(\mathrm{T} 2)$ & SWL (T1) & SWL (T2) & Gender & Age \\
\hline PEI & 3.47 & 0.41 & & $.59^{* * *}$ & $.35^{* * *}$ & $.52^{* * *}$ & $.49^{* * *}$ & .02 & -.01 \\
\hline $\begin{array}{l}\text { Positivity } \\
\text { ratio (T1) }\end{array}$ & 1.51 & 0.76 & & & $.64^{* * *}$ & $.61^{* * *}$ & $.61^{* * *}$ & .03 & .08 \\
\hline $\begin{array}{l}\text { Positivity } \\
\text { ratio (T2) }\end{array}$ & 1.59 & 1.11 & & & & $.40^{* * *}$ & $.53^{* * *}$ & -.11 & $.17^{\dagger}$ \\
\hline $\begin{array}{l}\text { Satisfaction } \\
\text { with life (T1) }\end{array}$ & 4.04 & 1.29 & & & & & $.83^{* * *}$ & .06 & -.02 \\
\hline $\begin{array}{l}\text { Satisfaction } \\
\text { with life (T2) }\end{array}$ & 4.25 & 1.28 & & & & & & .05 & .07 \\
\hline
\end{tabular}

Note. PEI - perceived emotional intelligence, PR - positivity ratio, SWL - satisfaction with life, T1, T2 - first and second measurement. Gender is coded: $0=$ men, $1=$ women. Positivity ratio = positive affect/negative affect.

${ }^{* * *} p<.001$ (two-tailed), ${ }^{\dagger} p<.10$

itive affect at the beginning of the week, and higher on Thursday and Friday) and negative affect (highest negative affect from Monday to Wednesday), and showed that at least for negative affect this rhythmicity was more important than the circadian (daily) rhythm. Second, following Baker, Thomas, Thomas, and Owens (2007), the selection of a week period was aimed at minimising recall errors and the likelihood of responses being based on an individual's generalised beliefs about their affect (as it was intended in the first measurement), and it increases the possibility of detection of more subtle changes in affect over time, which could be more problematic when taking longer periods, like years (cf. Sánchez-Álvarez et al., 2016).

\section{MEASURES}

The self-rated emotional intelligence scale, SREIS (Brackett et al., 2006) was used as in Study 1. The reliability of SREIS in this study was, $\alpha=.72$.

The Polish adaptation of PANAS (Positive and Negative Affect Schedule), SUPIN (Brzozowski, 2010). A version for measuring current emotional states was used, which consisted of 20 affect labels of positive (e.g. active, brisk, enthusiastic; in Polish: aktywny, żwawy, zapalony) and negative states (e.g. guilty, nervous, worried; in Polish: winny, nerwowy, zmartwiony). In the first measurement instruction, the participants were asked to indicate in their answers how they felt in general, and in the second measurement they were asked to refer only to their feelings of the past week. The participants rated each item on a seven-point Likert-type scale ranging from $1=$ not at all or slightly to $7=$ strongly, referring to each affective state. In the present study the following reliabilities were obtained: for general positive affect, $\alpha=.88$; for general negative affect, $\alpha=.89$; for Time 2 positive affect, $\alpha=.94$; and for the Time 2 negative affect, $\alpha=.89$.

The satisfaction with life scale, SWLS (Diener et al., 1985; Polish adaptation: Juczyński, 2001). The participants were twice asked to rate the items in terms of how they felt about them at that very moment. In the present study, the reliability of the first measurement was, $\alpha=.84$., and $\alpha=.86$ in the second one.

\section{RESULTS}

Descriptive statistics for perceived emotional intelligence, positivity ratios, and satisfaction with life are presented in Table 2.

The participants rated the general positive affect significantly higher, $M=4.26, S D=1.01$, than the general negative affect, $M=3.32, S D=1.17$, $t(99)=5.06, p<.001, d=.55$. The general positivity ratio ranged from 0.32 to 3.78 . The participants rated the positive affect in the past week significantly higher, $M=3.97, S D=1.37$, than the past week negative affect, $M=3.24, S D=1.36, t(99)=3.08, p=.003$, $d=.29$. The past week positivity ratio ranged from 0.16 to 5.18 . In comparison with general evaluations, the participants rated their weekly positive affect lower, $t(99)=2.87, p=.005$.

The regression analysis with bootstrap procedures implemented in the PROCESS macro was carried out to estimate indirect effects (Hayes, 2013). Model 6 with three mediators was used, where general positivity ratio was the first mediator, satisfaction with life (Time 1) was the second mediator, and positivity ratio (Time 2) was the third one, while satisfaction with life in the past week (Time 2) was the dependent variable. Age and gender were controlled for. 
The bias corrected confidence interval estimation method and 10,000 bootstrapping samples were used.

Satisfaction with life (Time 1) was predicted in $42 \%$ by PEI and general positivity ratio, when controlled for age and gender. When general positivity ratio was entered into the regression model, the path coefficient between PEI and satisfaction with life (Time 1) dropped from $b=1.63, S E=.27, t=5.97$, $p<.001, \beta=.52$ to $b=0.76, S E=.31, t=2.49, p=.014$, $\beta=.24$, and the indirect effect of PEI $\rightarrow$ general positivity ratio $\rightarrow$ satisfaction with life (Time 1 ) was significant, $b=0.87, \mathrm{SE}=.22,95 \% \mathrm{CI}=[0.49 ; 1.36]$. Positivity ratio (Time 2) was explained in $41 \%$ by $\mathrm{PEI}$, general positivity ratio, and satisfaction with life (Time 1). When general positivity ratio and satisfaction with life (Time 1) were entered into the model, the path coefficient between PEI and positivity ratio (Time 2) dropped from $b=0.94, S E=.25, t=3.71$, $p<.001, \beta=.35$ to non-significant, $b=-0.14, S E=.27$, $t=-0.53, p=.597, \beta=-.05$, and the indirect effects of PEI $\rightarrow$ positivity ratio (Time 1$) \rightarrow$ positivity ratio (Time 2) were significant, $b=1.03, S E=.26,95 \%$ $\mathrm{CI}=[0.59 ; 1.64]$, whereas the indirect effect of PEI $\rightarrow$ satisfaction with life (Time 1$) \rightarrow$ positivity ratio (Time 2) was non-significant, $b=0.05, S E=.13,95 \%$ $\mathrm{CI}=[-.20 ; .33]$.

The total regression model for satisfaction with life (Time 2) was significant, adj. $R^{2}=.73, F(6,93)=46.23$, $p<.001$. The direct effect of PEI on satisfaction with life (Time 2) was non-significant, $b=0.10, S E=.21$, $t=0.50, p=.618, \beta=.03$. Positive ratio (Time 2) was a significant predictor of satisfaction with life (Time 2), $b=0.27, S E=.08, t=3.40, p<.001, \beta=.24$, and the strongest predictor was satisfaction with life (Time 1), $b=0.72, S E=.07, t=10.69, p<.001, \beta=.73$. Three indirect effects appeared to be significant, namely: (a) PEI $\rightarrow$ satisfaction with life (Time 1$) \rightarrow$ satisfaction with life (Time 2), $b=0.55, S E=.26,95 \%$ $\mathrm{CI}=[0.06 ; 1.08],(\mathrm{b}) \mathrm{PEI} \rightarrow$ general positivity ratio $\rightarrow$ satisfaction with life (Time 1$) \rightarrow$ satisfaction with life (Time 2), $b=0.63, S E=.18,95 \% \mathrm{CI}=[0.33 ; 1.07]$, and (c) $\mathrm{PEI} \rightarrow$ general positivity ratio $\rightarrow$ positivity ratio (Time 2) $\rightarrow$ satisfaction with life (Time 2), $b=0.28$, $S E=.10,95 \% \mathrm{CI}=[0.13 ; 0.54]^{3}$. The indirect effect of $\mathrm{PEI} \rightarrow$ general positivity ratio $\rightarrow$ satisfaction with life (Time 1) $\rightarrow$ satisfaction with life (Time 2) was also significantly stronger than the indirect effect of PEI $\rightarrow$ general positivity ratio $\rightarrow$ positivity ratio (Time 2) $\rightarrow$ satisfaction with life (Time 2), $b=0.35$, $S E=.19,95 \% \mathrm{CI}=[0.02 ; 0.76]$. Standardised beta coefficients for the final model are presented in Figure 1B.

\section{DISCUSSION}

The second study again confirmed the significance of the positive relationships between perceived emotional intelligence and the positivity ratio, as well as between positivity ratio and satisfaction with life. Similarly to the results of the two-year study by Sánchez-Álvarez et al. (2016), it was demonstrated that emotional intelligence is predictive for estimations of satisfaction with life also in a short, weekly interval. A closer examination of the obtained results showed that the relationships between PEI and satisfaction with life are mediated by positive ratios, both general and in a weekly interval, but also by a primary evaluation of satisfaction with life. One should note that a substantial amount of statistical significance of the indirect effect concerning general positive ratio and primary satisfaction with life as mediators is due to the stability of subjective affective and cognitive well-being between the first and the second measurement. Lucas and Donnellan (2007) on a national level showed that up to $38 \%$ of the variance in stability of satisfaction with life is trait variance, which does not change over time, but about $34 \%$ of the variance can be accounted for by the autoregressive trait, which is only moderately stable over time. Schimmack and Oishi (2005) demonstrated that life satisfaction judgments are more heavily based on chronically accessible rather than temporarily accessible information. The mentioned results aroused some possible explanations of the obtained significance of indirect effects with a role of stability in positive ratios and satisfaction with life. Firstly, perceived emotional intelligence could be correlated with other trait-like predictors of situational judgements of life satisfaction or affective well-being. One potential factor here could be attachment. Kafetsios (2004) demonstrated that the quality of attachment is predictive for emotional abilities, and Guarnieri, Smorti, and Tani (2014) showed that attachment with parents, but mainly with one's romantic partner, is a positive predictor of satisfaction with life. Given that emotional intelligence plays an important role in navigating in romantic relationships (Zeidner \& Kloda, 2013), it could be seen that some third-party variables may simultaneously facilitate the development of emotional abilities and create beneficial personality contexts for their application in social relationships. Secondly, perceived emotional intelligence could facilitate or even encompass some chronically accessible beneficial cognitive models of self or/and others, which helps to obtain positive reinforcements from relations with other people. Some possible factors here may include self-esteem (Cheung, Cheung, $\&$ Hue, 2015) or meaning in life (Pereira-Teques, Bueno Carrera, Pais-Ribeiro, Teques, \& Ramón, 2016; Steger \& Kashdan, 2007). Thirdly, it is also possible that people with high perceived emotional intelligence are highly aware of the display rules in emotion expression (e.g. preference for consistency; Guadagno \& Cialdini, 2010), and hold their public displays of self-evaluations constant, which produces some kinds of artefacts in studies of a similar design to the ones used here. 


\section{GENERAL DISCUSSION}

The aim of these studies was to examine the role of positivity ratio in the relationship between perceived emotional intelligence and satisfaction with life. According to predictions, people with high perceived emotional intelligence also have higher positivity ratios as well as a higher life satisfaction. In both cross-sectional and short longitudinal designs, positivity ratios appeared to mediate between perceived emotional intelligence and satisfaction with life. The obtained results are in line with previous studies concerning the affective mediators between emotional intelligence and subjective well-being (Extremera \& Rey, 2016; Gignac, 2006; Kong \& Zhoa, 2013). In these studies, both trait emotional intelligence and ability emotional intelligence appeared to promote positive affect and decrease negative affect, which could be also visible through a higher positive ratio. According to Szczygieł and Mikolajczak (2017), emotional strategies of savouring and dampening might be utilised to keep the balance of positive to negative affect high and constant (cf. also Peña-Sarrionandia, Mikolajczak, \& Gross, 2015). Such an elevated affective balance, regardless of its proportion (e.g. 3 : 1; Fredrickson \& Losada, 2005; cf. the criticisms of Brown et al., 2013, 2014; $5: 1$; Gottman, 1994; or other approaches - cf. Schwartz et al., 2002), is indeed positively correlated with subjective cognitive well-being, and with life satisfaction, among others (Diener, Oishi, \& Lucas, 2003).

The second study also proved that perceived emotional intelligence might predict a positive ratio in a particular time interval. These results are similar to those obtained by Sánchez-Álvarez et al. (2016), but differ in respect to the width of the interval. While Sánchez-Álvarez et al. measured life satisfaction in a one-year period, in the current study it was rated for a one-week interval. Obtaining a similarly positive result in such a short perspective might mean that perceived emotional intelligence is not only correlated with chronic self-evaluations, but also with situational assessments. Although the effect sizes of the relationships between perceived emotional intelligence and positivity ratio or life satisfaction are not very large, this short-term positive association could confirm that emotional intelligence does foster daily functioning in a "micro-process" scale. Apart from the abovementioned emotional regulation process, another prominent candidate for explaining the mechanism of emotional intelligence operation at this level could be coping process (MacCann et al., 2011). In future research, a strong focus should be placed on the analysis of mediation mechanisms between emotional intelligence and positive affect, in cross-sectional, longitudinal (e.g. diary studies), and in experimental designs.
Current studies and previous analyses of the role of positivity ratio for life satisfaction used a trait-like measurement of positive and negative affect (e.g. PANAS; Kuppens et al., 2008; Watson, Clark, \& Tellegen, 1988). Hence, a genetic point of view toward affect may also shed some light on the results obtained in the present study, both in the correlational and SEM analyses. The two-factor theory of affect (Diener \& Emmons, 1984; Emmons \& Diener, 1985) posits that positive affect is more situational, while negative affect is more dispositional and probably genetically rooted. Recently, propositions of this theory were confirmed in a twin study by Zheng, Plomin, and von Stuum (2016). It was demonstrated that the intra-individual mean of negative affect across 40 days was substantially heritable (.49), while the intra-individual mean of positive affect across forty days was not substantially heritable (.18) but undergoes significant shared environment influences (.42). Intra individual variability of both negative (.50) and positive affect (.30) was significantly heritable. Given that positivity ratio combines two independent affective dimensions, which may arise in different ways (Diener \& Emmons, 1984), the consequently recognised preponderance of mediatory path between the perceived emotional intelligence and satisfaction with life through positive affect compared to the path, where negative affect is a mediating variable (e.g. Kong \& Zhao, 2013), may have resulted from a different operation of emotional intelligence on these two dimensions of affect. From this perspective, PEI may participate in optimisation of situational possibilities to feel positive emotion, whereas, for negative affect, PEI participates in a process of reducing vulnerability to aversive situations. A similar approach was proposed in exposure/reactivity processes of approach and avoidance motivation, where the approach motivation operates via increasing exposure to positive emotion-eliciting situations, and where avoidance motivation operates via increasing the reactivity to aversive situations (Bolger \& Schilling, 1991; Gable, 2006). Partial evidence for the line of reasoning that combines PEI and exposure/reactivity hypothesis comes from Athota and O'Connor's (2014) study. They demonstrated that perceived managing of ones own and others' emotional ability (a component of PEI) was inversely related with harm avoidance, which is saturated by avoiding motivation. More comprehensive confirmation comes from the recent study by Bacon and Corr (2017). The perceived emotional intelligence correlated positively with behavioural approach (components of drive and goal-drive persistence), but negatively with behavioural inhibition. According to this point of view, the mediating role of the positivity ratio covers two separate processes: increasing exposure to positive affect-inducing situations and reducing a more dispositionally evocated vulnerability to aversive stimuli. 
Some limitations in the current study should be considered. The first of them is the lack of information about the educational and material status of the participants in Study 1. As the study of Kong and Zhao (2013) showed, the socio-demographical variables do play a role in predicting life satisfaction, but they do not change the direction and power of the relationship between emotional intelligence and life satisfaction. In future studies, a potential moderator role of socio-economical variables in the investigating of emotional intelligence - positivity ratio - life satisfaction should be addressed. Secondly, the study failed to explicitly control for some unexpected and unusual events of the week that was the subject of assessment. The participants were asked to write down on their papers if anything unusual had happened in their lives during the week, but none of them wrote anything down. It could have resulted from the lack of such events, but also from the participants' low awareness. In future studies, the participants should be introduced with a more detailed query about their previous week or other intervals. Thirdly, the samples in the studies were predominantly people in emerging adulthood and with secondary or higher education, which may have restricted the variance of both positivity ratio and life satisfaction (cf. del Mar Salinas-Jiménez, Artes, \& Salinas-Jiménez, 2011). Fourthly, although based on the confirmation provided in the longitudinal study by Sánchez-Álvarez et al. (2016), the results obtained in the present study do not strongly support a causal path between emotional intelligence, positivity ratio, and satisfaction with life. In future research, carefully conducted experiments should give stronger evidence of causality in the considered relationship. Finally, the limitation of the studies was the difference in mean age of participants in both groups, and the wide age range of participants in Study 1. In the present analyses age and gender were controlled and appeared to be in a non-significant relationship with both mediating and dependent variables. Yet, according to age-related differences in positive and negative affect and satisfaction with life (Charles et al., 2001; Diehl et al., 2011; Kunzmann et al., 2013), in future research the developmental period should be examined as a moderator of relationships between PEI, affect, and satisfaction with life. However, the beneficial role of higher positive affect, and the higher positivity ratio for satisfaction with life and health, remain constantly important in later life (see Ong, Mroczek, \& Riffin, 2011).

The study showed that individuals with high perceived emotional intelligence reported greater satisfaction with their lives, and obtained and maintain a higher positivity ratio (the ratio of positive to negative affect). The positivity ratio was also confirmed to have a mediatory effect between perceived emotional intelligence and satisfaction with life.

\section{ENDNOTES}

1 Sample sizes have been also chosen for optimisation of statistical power on analyses. In the first study a power of 1.00 was achieved (with four predictors, and $\alpha$ set to .001 , and adj. $\left.R^{2}=.24\right)$, and in the second study the power was also 1.00 (with six predictors, and $\alpha$ set to .001 , and adj. $R^{2}=.73$ ).

2 According to the procedure used by Basińska and Gruszczyńska (2017), quadratic effects of positivity ratio were proved to be significant, $\Delta R^{2}=.05$, $F(1,310)=20.21, p<.001, b=-.31, \beta=-.27, f^{2}=.06$, and the inflection point was also around 2.20. The scatterplot for this relationship is available from the author upon request. The quadratic effect of positivity ratio was also significantly predicted by PEI, $b=.33, S E=.14, t=2.28, p=.023, \beta=.13$.

3 According to the procedure used by Basińska and Gruszczyńska (2017), quadratic effects of the general positivity ratio and the past week positivity ratio on the general SWLS and past week SWLS were proven to be non-significant in the present study, $\Delta R^{2}=.01, F(1,97)=1.04, p=.310, b=-.08$, and $\Delta R^{2}=.01, F(1,97)=0.71 ; p=.402, b=-.05$, respectively.

\section{REFERENCES}

Andrei, F., Siegling, A. B., Aloe, A. M., Baldaro, B., \& Petrides, K. V. (2016). The incremental validity of the Trait Emotional Intelligence Questionnaire (TEIQue): A systematic review and meta-analysis. Journal of Personality Assessment, 98, 261-276.

Athota, V. S., \& O'Connor, P. J. (2014). How approach and avoidance constructs of personality and trait emotional intelligence predict core human values. Learning and Individual Differences, 31, 51-58.

Bacon, A., \& Corr, P. J. (2017). Motivating emotional intelligence: A Reinforcement Sensitivity Theory (RST) perspective. Motivation and Emotion, 41, 254-264.

Baird, B. M., Lucas, R. E., \& Donnellan, M. B. (2010). Life satisfaction across the lifespan: Findings from two nationally representative panel studies. Social Indicators Studies, 99, 183-203.

Baker, R., Thomas, S., Thomas, P. W., \& Owens, M. (2007). Development of an Emotional Processing Scale. Journal of Psychosomatic Research, 62, 167-178.

Basińska, B. A., \& Gruszczyńska, E. (2017). Positivity and job burnout in emergency personnel: examining linear and curvilinear relationship. Polish Psychological Bulletin, 48, 212-219.

Bolger, N., \& Schilling, E. A. (1991). Personality and the problems of everyday life: The role of Neuroticism in exposure and reactivity to daily stresors. Journal of Personality, 59, 355-386. 
Brackett, M. A., Rivers, S. E., Shiffman, S., Lerner, N., \& Salovey, P. (2006). Relating emotional abilities to social functioning: A comparison of self-report and performance measures of emotional intelligence. Journal of Personality and Social Psychology, 91, 780-795.

Brown, N. J. L., Sokal, A. D., \& Friedman, H. L. (2014). The persistence of wishful thinking. American Psychologist, 69, 629-632.

Brown, N. J., Sokal, A. D., \& Friedman, H. L. (2013). The complex dynamics of wishful thinking: The critical positivity ratio. American Psychologist, 68, 801-813.

Brzozowski, P. (2010). Skala uczuć pozytywnych i negatywnych (SUPIN): Polska adaptacja skali PANAS Dawida Watsona i Lee Anny Clark. Podręcznik [SUPIN. Positive and negative affect schedule (PANAS)]. Warsaw: Pracownia Testów.

Charles, S. T., Reynolds, C. A., \& Gatz, M. (2001). Age-related differences and change in positive and negative affect over 23 years. Journal of Personality and Social Psychology, 80, 136-151.

Cheung, Ch.-K., Cheung, H. Y., \& Hue, M.-T. (2015). Emotional intelligence as a basis for self esteem in young adults. The Journal of Psychology. Interdisciplinary and Applied, 149, 63-84.

Cornélissen, G., Watson, D., Mitsutake, G., Fišer, B., Siegelová, J., Dušek, J., Vohlídalová, I., Svaèinová, H., \& Halberg, F. (2005). Mapping of circaseptan and circadian changes in mood. Scripta Medica (BRNO), 78, 89-98.

del Mar Salinas-Jiménez, M., Artes, J., \& SalinasJiménez, J. (2011). Education as a positional good: A life satisfaction approach. Social Indicators Research, 103, 409-426.

Diehl, M., Hay, E. L., \& Berg, K. M. (2011). The ratio between positive and negative affect and flourishing mental health across adulthood. Aging and Mental Health, 15, 882-893.

Diener, E. (2000). Subjective well-being: The science of happiness and a proposal for a national index. American Psychologist, 55, 34-43.

Diener, E., Colvin, C. R., Pavot, W. G., \& Allman, A. (1991). The psychic costs of intense positive affect. Journal of Personality and Social Psychology, 61, 492-503.

Diener, E., \& Emmons, R. A. (1984). The independence of positive and negative affect. Journal of Personality and Social Psychology, 47, 1105-1117.

Diener, E., Emmons, R. A., Larsen, R. J., \& Griffin, S. (1985). The satisfaction with life scale. Journal of Personality Assessment, 49, 71-75.

Diener, E., Oishi, S., \& Lucas, R. E. (2003). Personality, culture, and subjective well-being: Emotional and cognitive evaluations of life. Annual Review of Psychology, 54, 403-425.

Diener, E., Sandvik, E., \& Pavot, W. G. (1990). Happiness is the frequency, not intensity, of positive versus negative affect. In F. Strack, M. Argyle, \& N. Schwarz (Eds.), The social psychology of subjective well-being (pp. 119-139). Elmsford, NY: Pergamon Press.

Elfenbein, H. A., \& MacCann, C. (2017). A closer look at ability emotional intelligence (EI): What are its component parts, and how do they relate to each other? Social and Personality Psychology Compass, 11, e12324.

Emmons, R. A., \& Diener, E. (1985). Personality correlates of subjective well-being. Personality and Social Psychology Bulletin, 11, 89-97.

Extremera, N., \& Fernández-Berrocal, P. (2005). Perceived emotional intelligence and life satisfaction: Predictive and incremental validity using the Trait Meta-Mood Scale. Personality and Individual Differences, 39, 937-948.

Extremera, N., Ruiz-Aranda, D., Pineda-Galán, C., \& Salguero, J. M. (2011). Emotional intelligence and its relation with hedonic and eudaimonic well-being: A prospective study. Personality and Individual Differences, 51, 11-16.

Extremera, N., \& Rey, L. (2016). Ability emotional intelligence and life satisfaction: Positive and negative affect as mediators. Personality and Individual Differences, 102, 98-101.

Fredrickson, B. (2013). Updated thinking on positivity ratios. American Psychologist, 68, 814-822.

Fredrickson, B. L., \& Losada, M. F. (2005). Positive affect and the complex dynamics of human flourishing. American Psychologist, 60, 678-686.

Gable, S. L. (2006). Approach and avoidance social motives and goals. Journal of Personality, 74, 175-222.

Gallagher, E. N., \& Vella-Brodrick, D. A. (2008). Social support and emotional intelligence as predictors of subjective well-being. Personality and Individual Differences, 44, 1551-1561.

Gignac, G. E. (2006). Self-reported emotional intelligence and life satisfaction: Testing incremental predictive validity hypotheses via structural equation modeling (SEM) in a small sample. Personality and Individual Differences, 40, 1569-1577.

Gottman, J. M. (1994). What predicts divorce? The relationship between marital processes and marital outcomes. New York, NY: Erlbaum.

Guadagno, R. E., \& Cialdini, R. B. (2010). Preference for consistency and social influence: A review of current research findings. Social Influence, 5, 152-163.

Guarnieri, S., Smorti, M., \& Tani, F. (2014). Attachment relationships and life satisfaction during emerging adulthood. Social Indicators Research, 121, 833-847.

Hayes, A. F. (2013). Introduction to mediation, moderation, and conditional process analysis: a regression-based approach. New York: Guilford Press.

Jaworowska, A., \& Matczak, A. (2001). Kwestionariusz Inteligencji Emocjonalnej INTE N. S. Schutte, J. M. 
Malouffa, L. E. Hall, D. J. Haggerty'ego, J. T. Cooper, C. J. Goldena, L. Dornheim. Podręcznik [INTE. Emotional Intelligence Questionnaire by N. S. Schutte, J. M. Mallouff, L. E. Hall, D. J. Haggerty, J. T. Cooper, C. J. Golden, L. Dornheim. Manual]. Warsaw: Pracownia Testów Psychologicznych PTP.

Juczyński, Z. (2001). Narzędzia pomiaru w promocji i psychologii zdrowia [Assessment and diagnostic instruments for health psychology promotion]. Warsaw: Pracownia Testów Psychologicznych Polskiego Towarzystwa Psychologicznego.

Kafetsios, K. (2004). Attachment and emotional intelligence abilities across the life course. Personality and Individual Differences, 37, 129-145.

Karademas, E. C. (2007). Positive and negative aspects of well-being: common and specific predictors. Personality and Individual Differences, 43, 277-287.

Kong, F., \& Zhao, J. (2013). Affective mediators of the relationship between trait emotional intelligence and life satisfaction in young adults. Personality and Individual Differences, 54, 197-201.

Kunzmann, U., Richter, D., \& Schmukle, S. C. (2013). Stability and change in affective experience across the adult life-span: Analyses with a national sample from Germany. Emotion, 13, 1086-1095.

Kuppens, P., Realo, A., \& Diener, E. (2008). The role of positive and negative emotions in life satisfaction judgment across nations. Journal of Personality and Social Psychology, 95, 66-75.

Lee, E., Watson, E., \& Dams-O’Connor, K. (2017). Positive affect as a mediator of the relationship between social contact and subjective health. Archives of Physical Medicine and Rehabilitation, 98, e11.

Lucas, R. E., Diener, E., \& Suh, E. (1996). Discriminant validity of well-being measures. Journal of Personality and Social Psychology, 71, 616-628.

Lucas, R. E., \& Donnellan, M. B. (2007). How stable is happiness? Using the STARTS model to estimate the stability of life satisfaction. Journal of Research in Personality, 41, 1091-1098.

MacCann, C., Fogarty, G. J., Zeidner, M., \& Roberts, R. D. (2011). Coping mediates the relationship between emotional intelligence (EI) and academic achievement. Contemporary Educational Psychology, 36, 60-70.

Martins, A., Ramalho, N., \& Morin, E. (2010). A comprehensive meta-analysis of the relationship between emotional intelligence and health. Personality and Individual Differences, 49, 554-564.

Mayer, J. D., Roberts, R. D., \& Barsade, S. G. (2008). Human abilities: Emotional intelligence. Annual Review of Psychology, 59, 507-536.

Mayer, J. D., \& Salovey, P. (1997). What is emotional intelligence? In P. Salovey \& D. Sluyter (eds.), Emotional development and emotional intelligence: Implications for educators (pp. 3-31). New York: Basic Books.
Mayer, J. D., Salovey, P., \& Caruso, D. R. (2002). MayerSalovey-Caruso emotional intelligence test (MSCEIT), version 2.0. Toronto, Canada: Multi-Health Systems.

Ong, A. D., Mroczek, D. K., \& Riffin, C. (2011). The health significance of positive emotions in adulthood and later life. Social and Personality Psychology Compass, 5, 538-551.

Palmer, B., Donaldson, C., \& Stough, C. (2002). Emotional intelligence and life satisfaction. Personality and Individual Differences, 33, 1091-1100.

Peña-Sarrionandia, A., Mikolajczak, M., \& Gross, J. J. (2015). Integrating emotion regulation and emotional intelligence traditions: A meta-analysis. Frontiers Psychology, 6, 160.

Pereira-Teques, A., Bueno Carrera, G., Pais-Ribeiro, J., Teques, P., \& Ramón, G. L. (2016). The importance of emotional intelligence and meaning in life in psycho-oncology. Psychooncology, 25, 324-331.

Petrides, K. V. (2011). Ability and trait emotional intelligence. In T. Chamorro-Premuzic, A. Furnham, \& S. von Stumm (eds.), The Wiley-Blackwell handbook of individual differences (pp. 656-678). New York: Wiley.

Petrides, K. V., \& Furnham, A. (2000). On the dimensional structure of emotional intelligence. Personality and Individual Differences, 29, 313-320.

Rego, A., Sousa, F., Marques, C., \& Cunha, M. P. E. (2012). Optimism predicting employees' creativity: The mediating role of positive affect and the positivity ratio. European Journal of Work and Organizational Psychology, 21, 244-270.

Saklofske, D. H., Austin, E. J., \& Minski, P. S. (2003). Factor structure and validity of a trait emotional intelligence measure. Personality and Individual Differences, 34, 707-721.

Salovey, P., Mayer, J. D., Goldman, S. L., Turvey, C., \& Palfai, T. P. (1995). Emotional attention, clarity, and repair: Exploring emotional intelligence using the Trait Meta-Mood Scale. In J. W. Pennebaker (Ed.), Emotion, disclosure, \& health (pp. 125-154). Washington: American Psychological Association.

Salovey, P., Bedell, B., Detweiler, J., \& Mayer, J. (1999). Coping intelligently: Emotional intelligence and the coping process. In C. Snyder (Ed.), Coping: The psychology of what works (pp. 141-164). New York: Oxford Psychology Press.

Sánchez-Álvarez, N., Extremera, N., \& FernándezBerrocal, P. (2015). Maintaining life satisfaction in adolescence: Affective mediators of the influence of perceived emotional intelligence on overall life satisfaction judgments in a two-year longitudinal study. Frontiers in Psychology, 6, 1892.

Sánchez-Álvarez, N., Extremera, N., \& FernándezBerrocal, P. (2016). The relation between emotional intelligence and subjective well-being: A meta-analytic investigation. The Journal of Positive Psychology, 11, 276-285. 
Schimmack, U., \& Oishi, S. (2005). The influence of chronically and temporarily accessible information on life satisfaction judgments. Journal of Personality and Social Psychology, 89, 395-406.

Schimmack, U., Diener, E., \& Oishi, S. (2002). Life-satisfaction is a momentary judgment and a stable personality characteristic: The use of chronically accessible and stable sources. Journal of Personality, 70, 345-384.

Schimmack, U., Radhakrishnan, P., Oishi, S., Dzokoto, V., \& Ahadi, S. (2002). Culture, personality, and subjective well-being: Integrating process models of life satisfaction. Journal of Personality and Social Psychology, 82, 582-593.

Schutte, N. S., Malouff, J. M., Hall, L. E., Haggerty, D. J., Cooper, J. T., Golden, C. J., \& Dornheim, L. (1998). Development and validation of a measure of emotional intelligence. Personality and Individual Differences, 25, 167-177.

Schutte, N. S., \& Malouff, J. M. (2011). Emotional intelligence mediates the relationship between mindfulness and subjective well-being. Personality and Individual Differences, 50, 1116-1119.

Schutte, N. S., Malouff, J. M., Thorsteinsson, N. B., \& Rooke, S. E. (2007). A meta-analytic investigation of the relationship between emotional intelligence and health. Personality and Individual Differences, 42, 921-933.

Schwarz, N., \& Clore, G. L. (2007). Feelings and phenomenal experiences. In A. Kruglanski \& E. T. Higgins (Eds.), Social psychology. Handbook of basic principles ( $2^{\text {nd }}$ ed.) (pp. 385-407). New York: Guilford.

Schwartz, R. M., Reynolds, C. F., Thase, M. E., Frank, E., Fasicska, A. L., \& Haaga, D. A. F. (2002). Optimal and normal affect balance in psychotherapy of major depression: Evaluation of the balanced states of mind model. Behavioural and Cognitive Psychotherapy, 30, 439-450.

Shrira, A., Palgi, Y., Wolf, J. J., Haber, Y., Goldray, O., Shacham-Shmueli, E., \& Ben-Ezra, M. (2011). The positivity ratio and functioning under stress. Stress and Health, 27, 265-271.

Steger, M. F., \& Kashdan, T. B. (2007). Stability and specificity of meaning in life and life satisfaction over one year. Journal of Happiness Studies, 8, 161-179.

Szczygieł, D., \& Mikolajczak, M. (2017). Why are people high in emotional intelligence happier? They make the most of their positive emotions. Personality and Individual Differences, 117, 177-181.

Szczygieł, D., \& Weber, J. (2017). Emotional intelligence predicts peer-rated social competence above and beyond personality traits. Current Issues in Personality Psychology, 5, 91-101.

Watson, D., Clark, L. A., \& Tellegen, A. (1988). Development and validation of a brief measure of positive and negative affect: The PANAS scales.
Journal of Personality and Social Psychology, 54, 1063-1070.

Wojciszke, B., \& Baryła, W. (2005). Skale do pomiaru nastroju i sześciu emocji [Scales for measurement of mood and six emotions]. Czasopismo Psychologiczne, 11, 31-47.

Wong, C. S., \& Law, K. S. (2002). The effects of leader and follower emotional intelligence on performance and attitude: An exploratory study. The Leadership Quarterly, 13, 243-274.

Zeidner, M., \& Kloda, I. (2013). Emotional intelligence (EI), conflict resolution patterns, and relationship satisfaction: Actor and partner effects revisited. Personality and Individual Differences, 54, 278-283.

Zeidner, M., \& Matthews, G. (2016). Ability emotional intelligence and mental health: Social support as a mediator. Personality and Individual Diffrences, 99, 196-199.

Zeidner, M., Matthews, G., \& Roberts, R. D. (2006). Emotional intelligence, adaptation, and coping. In J. Ciarrochi, J. Forgas, \& J. D. Mayer (Eds.), Emotional intelligence in everyday life: A scientific inquiry (2 ${ }^{\text {nd }}$ ed.) (pp. 100-125). Philadelphia, PA: Psychology Press.

Zeidner, M., Matthews, G., \& Roberts, R. D. (2012). The emotional intelligence, health, and well-being nexus: What have we learned and what have we missed? Applied Psychology: Health and Well-being, 4, 1-30.

Zheng, Y., Plomin, R., \& von Stuum, S. (2016). Heritability of intraindividual mean and variability of positive and negative affect: Genetic analysis of daily affect ratings over a month. Psychological Science, 27, 1611-1619. 